\title{
Actors and Responsibilities of the Educational Process
}

\author{
María de Jesús Velázquez Vázquez ${ }^{1}$, Martín Darío Castillo Sánchez ${ }^{1,}$, Horacio Sánchez Barcenas ${ }^{2}$ \\ ${ }^{1}$ National Polytechnic Institute, Higher School of Mechanical and Electrical Engineering - Zacatenco, Communications and Electronics \\ Engineering, Mexico City, Mexico \\ ${ }^{2}$ National Polytechnic Institute, Higher School of Economics, Professional Unit "Lázaro Cárdenas", Mexico City, Mexico
}

Email address:

mdj_vv@yahoo.com.mx (M. de J. Velázquez), avinfer@hotmail.com (M. Castillo), hbarcenas@ipn.mx (H. Sánchez)

${ }^{*}$ Corresponding author

\section{To cite this article:}

María de Jesús Velázquez Vázquez, Martín Darío Castillo Sánchez, Horacio Sánchez Barcenas. Actors and Responsibilities of the Educational Process. Science Journal of Education. Vol. 5, No. 3, 2017, pp. 100-104. doi: 10.11648/j.sjedu.20170503.14

Received: January 19, 2017; Accepted: March 31, 2017; Published: April 12, 2017

\begin{abstract}
The educational issue has always been the subject of intense debate on the part of researchers, government and specialists in the subject. Lately, the discussion has focused on the scope and limits of education systems, that is, the educational apparatus has responded so much to the resolution of problems that afflict society as a whole. One of the strongest critics revolves around the evaluation process, the most compelling argument being that the ways of evaluating are no longer the most convenient according to the times in which we live, this on the one hand, on the one hand, all the actors involved in the education must be subject to the evaluation including the same institutions, not only the students and teachers, so it seems that there is a total separation of the planning-evaluation processes. The purpose is to make a series of reflections and considerations about the evaluation process and the main actors involved in it.
\end{abstract}

Keywords: Education, Process, Actors, Student

\section{Introduction}

"The systematic and flexible processes of educational planning that transform the individual and social dimensions of reality at a time when the protagonists are recognized institutionally identified by the educational project" [1].

The educational issue has always been the subject of intense debate by researchers, government and specialists in the subject. Lately the discussion has focused on the scope and limits of education systems, that is, that the educational apparatus has responded so much to the resolution of problems that afflicts society as a whole. One of the strongest criticisms revolves around the evaluation process, the most compelling argument being that the ways of evaluating are no longer the most convenient according to the times in which we live, on the one hand. That all actors involved in education must be subject to evaluation including the same institutions, not just students and teachers, it seems that there is a total separation of planning-evaluation processes. The purpose of this paper is to make a series of reflections and considerations about the evaluation process and the main actors that intervene in it. A common assumption is that a central task of teaching is to deliver (or a computer to download) content for students, who then store that content in their minds for later retrieval and use. The personality of the teacher and student in such a paradigm is lost, because the focus of the educational activity becomes content instead of creating an interpersonal context that encourages learning. Several theorists have questioned the assumption of "downloading", arguing that learning is built, rather than simply surrender. In this alternative Paradigm, students who are exposed to the content and ideas imparted by the teacher will construct meaning of those ideas, connecting them with previous experiences and knowledge, evaluating them and making judgments about them. In this paradigm, relationships become important because they provide the context of meaning construction and, therefore, the construction of learning. Richard Tiberius describes the importance of Relation in this process. Several theorists and researchers of the educational literature have observed that in order to develop high quality between student and teacher the relationships are associated with the students' intrinsic motivation to learn. These relationships have the effects both on learning and on the sense of social identification of 
students. This aspect of "teacher-training" student teacher can have powerful effects on the choices and professional behaviors of students, and can be exploited by the teacher who attends the personality of themselves and the student. In this research as used techniques of documental investigation and consultation of governmental sources.

\section{Development}

\subsection{International Context}

Employment policies at the national level, as well as the phenomenon of economic and information globalization, is very simple, it is said that the freedom of market forces and competition can ensure improved quality in education. It is clear that in these processes of globalization is centrally determining the educational problem, this means that the least that can be said is that education systems cannot ignore these major trends; and also that we must in its ethical sense involve us in the transformation of its processes and above all. We must pay attention in the way in which education in its different modalities can provide a critical vision, in order to guide the social process and train citizens capable of contributing to better forms of human growth and development [3].

The construction of the concept of quality directly influences efforts to make it the path and goal of education. We move in a globalized, increasingly demanding and competitive environment that, in the face of the power of money, opposes the power of knowledge as the axis and engine of society. Therefore, education reaches a leading role in the economic and social development of countries; we speak of course of a quality education that allows being really competent to the students.

\subsection{The Challenges to Be Faced}

In the so-called knowledge society, the preparation of the new generations for their incorporation into the world of work and public life requires the intervention of specific institutions such as the school. This is progressively inducing in students the ideas, knowledge representations, dispositions and modes of behavior required by society, for this reason education needs profound changes, which must be geared to meet the needs of a changing and evolving society. The necessary reconstruction of the historical moments through which the conceptualization of education has gone through generally reflects the characteristics of the formal education they represent. Now, viewed from a more concrete angle, it is necessary to reflect and ask ourselves whether the educational systems in Mexico are efficient and to what extent they contribute to the improvement in the living standards of their population. The traditional school was a way perfectly suited to the needs of its time and, in the modern sense. The vigor with which today subsists is correlative to the model of society that gave rise to it [4]. This leads us to rethink about the way in which the evaluation process is being carried out, an essential element to know if each of the actors that participate in the process of learning - teaching are fulfilling fully and efficiently with the role that it touches them. The main actors in this process are the students and teachers, each of them has a role and a responsibility to fulfill, and it depends largely on the strengthening of the educational apparatus and consequently the welfare of society. The new school requires relevant positions for educational action, and continues to be current. Although it presents a series of limitations, it is undeniable that it favors a different role for teachers and students. The mission of the teacher is to create working conditions that allow the student to develop their skills; for this, he uses transformations (not radical) in pedagogical techniques. The evaluation carried out by the OECD gives an overview of the structure of the integration of educational levels in Mexico and its zones, as well as the actors and the objectives of each one, as can be seen in Table 1 .

Table 1. Basic education figures, school year 2008-2009.

\begin{tabular}{llllll}
\hline $\begin{array}{l}\text { Education } \\
\text { level }\end{array}$ & Service & Students & Teachers & School & Group \\
\hline \multirow{4}{*}{ Preschool } & General & $4,099,655$ & 183,018 & 60,882 & 29,631 \\
& Indigenous & 383,006 & 17,035 & 9,468 & 19,045 \\
& Community & 151,751 & 18,153 & 19,045 & 268,068 \\
& Subtotal & $4,634,412$ & 218,206 & 89,395 & 634,068 \\
& General & $13,865,443$ & 520,178 & 77,470 & 64,053 \\
& Indigenous & 841,151 & 36,105 & 9,918 & 45,939 \\
& Community & 109,141 & 12,469 & 11,187 & 744,547 \\
& Subtotal & $14,815,735$ & 568,752 & 98,575 & 97,326 \\
& General & $3,124,446$ & 209,639 & 12,152 & 48,832 \\
& Technique & $1,741,412$ & 91,211 & 4,438 & 69,272 \\
& Distance & $1,255,524$ & 64,422 & 17,475 & 1,816 \\
& school & & & 315 & 217,246 \\
& For Workers & 32,077 & 4,276 & 315 \\
& Subtotal & $6,153,459$ & 369,548 & 34,380 & 219,392 \\
& Total & $25,603,606$ & $1,156,506$ & 222,350 & $1,229,861$ \\
\hline
\end{tabular}

* Report of the Evaluation of Basic Education in Mexico, 2010

Preschool education consist of three grades, the first for children of three years, the second for four years and the third for five years. This level has been compulsory since 2002. Its objective is to contribute to comprehensive training and ensure participation in educational experiences that allow the development of affective, social and cognitive competences in the following formative fields: personal and social development, language and Communication, mathematical thinking, exploration and world knowledge, artistic expression and appreciation, and physical development and health (SEP, 2004). At the national level, there are 4, 634,412 students, 218,206 teachers and 89,395 schools (SEP, 2009). Current coverage is $78 \%$.

Primary education is taught in six grades for children aged six to young people under the age of 15 , and at the end of the year, an official certificate is issued, which is an essential requirement to enter secondary school. This level is mandatory since 1917. Its objective is to provide and develop in students the necessary skills for their personal, social, scientific, civic and artistic training. At the national level, it comprises $14,815,735$ students, 568,752 teachers and 98,575 
schools. The students, $93.4 \%$ study in general primary schools (urban and rural), 5.6\% in indigenous (bilingualbicultural) and $1 \%$ in community courses (small communities). The schools, $78.5 \%$ are general primary schools, $10.1 \%$ are indigenous, and $11.4 \%$ are community center classrooms of the National Council for Educational Development (CONAFE). Half of indigenous primary schools, and at least three quarters of community courses are located in rural villages (INEE, 2005). The total primary, $44 \%$ are multi-grade organizations, all community courses, about 6,000 indigenous primary schools and 25,000 general primary schools, serve $9.5 \%$ of school enrollment at this level. This level is the most stable and consistent of all levels of education with a coverage of $97 \%$, a terminal efficiency of $93.8 \%$, a dropout rate of $1.1 \%$, and a failure rate of $3.8 \%$ (Presidency of the Republic, 2007, 2009). Currently, it is governed by the Plan and Programs of study of 2009.

Secondary education is taught in three grades, is aimed at young people between 13 and 15 years of age, and is accredited by official certificate, which is a requirement to enter upper secondary education. This level is mandatory since 1992. Its objective is the acquisition of knowledge, the development of skills and the construction of values and attitudes; And training in skills, based on the multicultural national context and the specificity of each regional, state and community context (SEP, 2006). At the national level, there are 6, 153,459 students, 369,548 teachers and 34,380 schools (SEP, 2009). The students, $50.7 \%$ study in general secondary schools, $28.1 \%$ in technical, $20.2 \%$ in telesecondary, and $1 \%$ in schools for workers. This level has a coverage of $95.2 \%$, a terminal efficiency of $80.9 \%$, a dropout rate of $6.8 \%$, and a failure rate of $15.5 \%$ (Presidency of the Republic, 2009). [5].

\subsection{Quality Is Another Big Problem}

According to assessments accomplished in Mexico, at PISA 2009, the average was 425 applications, $39 \%$ of students in reading, $51 \%$ in mathematics and $48 \%$ in science below level 2 (the basic), in the test.

$17.4 \%$ in primary and $52 \%$ in secondary below the basic level in mathematics. Although there was an improvement in primary and static behavior in secondary [6,7]. Figure 1 shows how the average terminal efficiency of the 2001-2004 generation is $45.03 \%$, which is low relative to the national average, however, only if the students of other schools are taken into account generations a terminal efficiency of $60.41 \%$ is achieved. To date, there has been no evaluation of accreditation and its impact on these indicators. These data were provided by the Quality Control Department of the Teaching-learning process.

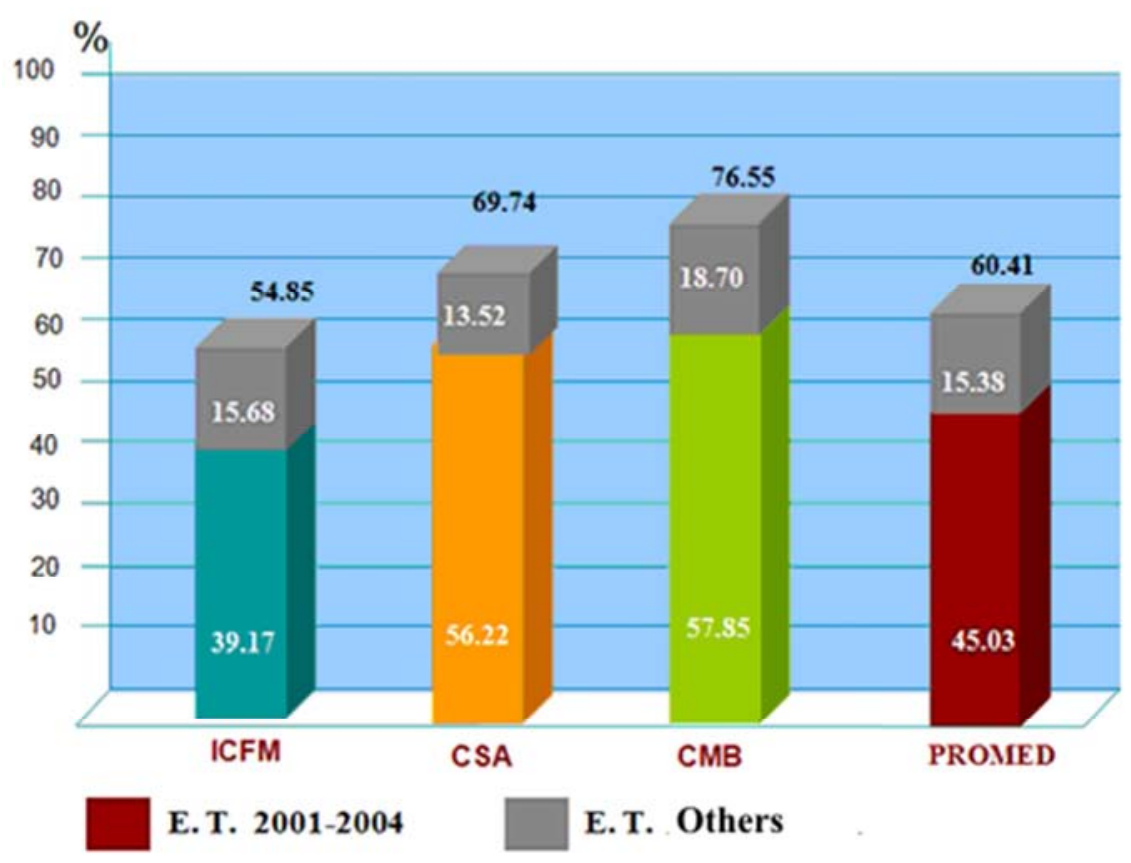

Figure 1. Terminal efficiency of upper middle level generation 2001 - 2004.

\subsection{Actors of the Learning Process}

The professional educator, such as the teacher, does this in a conscious and systematic way: he analyzes the educational fact, proposes goals and designs strategies that allow a group of people (commonly called students) to achieve concrete learning, but not only designs the process, but does what is planned without forgetting the evaluation process. In practice, the application of these principles has not been easy and has not had enough force to eradicate the Traditional School. In addition to the teacher, in Mexico there are several agencies that have the function of evaluating the learning of the students of the Education System, such as the National Assessment Center for Higher Education (CENEVAL), the same Ministry of Public Education (SEP), And the recently formed National Institute for the Evaluation of Education (INEE). However, these instances evaluate according to their own parameters, valid, but different from each other and 
without previously having been made known to public opinion, much less teachers and students as main actors of the teaching - learning process, and Instances of supervision, evaluation and control of educational quality.

The word qualification refers exclusively to the assessment of student behavior (school qualification). Qualifying, therefore, is a more restricted activity to evaluate. The qualification will be the qualitative (know / not know) or quantitative expression $(10,9,8$, etc.) of the value judgment we emit on the student's activity and achievements. In this value judgment, the student's degree of sufficiency, insufficiency, knowledge, skills and abilities are usually expressed as the result of some kind of test, activity, exam or process. [8, 9]. The assessment of learning requires a clear and objective assessment of what kind of behavior was learned in the educational process: it does not understand what it reads; it does not pronounce well, it cannot solve this type of problem, etc.

\subsection{The Qualification and the Evaluation}

The forms of evaluation in the traditional school were mere disciplinary mechanisms, which sought to gather information about the cognitive, but primarily behavioral, process of subjects [10]. The assessment of students school progress, at present, has shown a need for a more detailed and fair valuation system. The schemes with which many teachers work today are too mechanical, impartial or obtuse. The evolutionary processes that have undergone the academic evaluation of student progress since ancient times have been fully significant. In many cases it is not understood well enough what the evaluation process is in relation to the educational field, it is believed that the only ones that should be evaluated are the students, which is wrong since they must also be evaluated teachers and institutions themselves, otherwise we fall into error and it is thought that the only ones who are wrong are the students. Therefore, we can point out that the evaluation performs several functions, not only for the evaluated subject, but for the teacher, the school institution, the family and the social system as a whole. Good grades come by themselves if the subject matches the interests and concerns of the student. It is not that exams need to be eliminated, they can be a useful educational tool. But complementary, something that helps students improve on their own, or for instructors or others who need to know about what we do and tell us what we need to change. Passing exams cannot be compared to searching, investigating, engaging in topics that attract and stimulate us; The latter is much more practical than passing exams. And, in fact, if given the opportunity of this type of educational career, the student will remember what he discovered. Therefore, education should give the students a basis and from there learn for themselves [11].

Evaluation has no meaning in itself, but as a result of the set of relations between objectives, methods, pedagogical model, students, teacher, etc. Thus fulfilling a role in the regulation and control of the educational system, in the relationship of students with knowledge; of teachers with students, etc. Planning and evaluation are two inseparable elements as mentioned before, however, planning is an element that at least in its form does not change so quickly, not evaluation. There is debate in various forums on this subject and the conclusions have been very diverse, for example there are those who clearly state that a written examination is already overdue. The representation of the teaching condition and that of the student is totally different; The evaluative comparisons must be according to their cognitive level we speak of experience and level of maturation, the latter determinant of the degree of complex thinking between one and another, so that in the design of instruments teachers should think about the intellectual conditions of the students. In this way, the evaluation should contemplate a understanding process of student performance analysis, dynamic, critical, creative, cooperative, which presupposes constant accompaniment and takes into account the various dimensions of the student's performance. In this sense, it contributes to decision-making and to the improvement of the quality of teaching, and emphasizes an aspect of procedural diagnosis, informing the protagonists of the action for their constant improvement (Capelleti, 1999). [12]. The quality of education implies more than evaluating its results; It is also necessary to know the quality of the conditions and the processes in which the learning takes place. A good evaluation of the educational system requires, besides observing the students' learning, to know the schools, their resources, their operating conditions and their organizational processes. There is also a need for detailed knowledge about teachers and principals, their working conditions and their pedagogical capacity. In Mexico, the evaluation of schools and teachers does not yet have the degree of development of assessments of the quality of learning. There are, however, initiatives that provide a considerable amount of information, but progress must still be made in the development of more elaborate evaluation instruments and indicators. [13, 14].

\section{Discussion}

Talking about the educational issue is a holistic exercise, ie not only the teacher and students make up the main actors, the vision must be broadened and contemplate all the structures of the system, it is the evaluation that must be applied at all levels of the structure of the system. Education system with the objective of detecting when and who does not comply with the established indices, this influences the quality and quantity of terminal efficiency, which generates a low insertion of the graduates in the labor field, generating a negative impact on the companies Which, by not having qualified personnel, diminish the level of competitiveness among the countries that make up the OECD.

The qualification as a number applied to the students is no longer valid, it is necessary to design other instruments that help us to determine with certainty when the student has developed the programmed competences.

The evaluation should serve not only the teacher to know 
the skills developed but the student should be aware of the skills developed during their learning process to access more successfully the opportunities offered by the job market.

\section{Conclusion}

1. As we have seen in the development of the article, the international context requires us to face new changes in the entire educational structure, all accompanied by the evaluation process that integrates all the actors in the process.

2. The intentionality of the evaluation is fixed by the information needs for decision making, which tries to maximize the operation of an already existing program from the achievement of the objectives already proposed, the process streamlining, the cost reduction, the satisfaction of those who seek it, all simultaneously or a combination of them; which is rarely concerned with understanding the process of learning. On the other hand, the evaluation of cognitive experience should be advocated as a natural process in the student, since the student is seen as the main engine of his own progress. Behind any significant use of contemporary technology, such as the internet, communication systems, graphics or whatever, unless there is a well-designed, well-constructed conceptual apparatus behind it, it is unlikely to be useful, and even could be harmful. The person who wins the Nobel Prize is not the one who reads more articles and takes more notes; Is the person who knows what to look for. Cultivate that ability to look for what is meaningful and always be willing to question if we are on the right path that is what education should deal with, whether using computers and the internet or pencil, paper and books.

3. Education that is oriented toward improvement requires a democratic participation, that is, of the participation of all those involved in the evaluative process. As for the responsibility of the quality of teaching that is generally downloaded to the institution, many consider that the real responsible is the teacher since it is this one who finally interacts with the students, who has to interpret the situation without interference. He must use personal conditions to successfully implement the curriculum.

Only in this way can we aspire to make education an efficient system that allows us to be more competitive worldwide.

\section{References}

[1] Delgadillo Licea, Amneris (2001). Participatory diagnosis in institutions. Ed. Academic Spanish. Mexico.
[2] J Gen Intern Med. 2006 Jan; 21(Suppl 1): S16-S20. The Role of the Student Teacher Relationship in the Formation of Physicians.

[3] FIMPES (2006) Journal of the FIMPES Research Commission. Ed. New Season. Mexico. Consulted in August 2014.

http://www.fimpes.org.mx/phocadownload/RevistaCIF/Revist a-CIF-3.pdf

[4] Mejía Pérez, Omar (2012). From traditional assessment to a new competency-based assessment. Autonomous University of Fresnillo, Educare Electronic Magazine Vol. 16, No. 1. Cuernavaca, Morelos, Mexico.

[5] OCDE (2010). Review of Assessment and Evaluation Frameworks to Improve School Results. Report of the practices of the Evaluation of Basic Education in Mexico. Consulted on February 20, 2017. https://www.oecd.org/edu/school/CBR\%20Mexico\%20Spanis h.pdf

[6] Sylvia Schmelkes (2013). INEE. National Institute for the Evaluation of Education. Mexico.

[7] Gracia, Ma. Amalia, Horbath, Jorge E. (2014). The Educational Evaluation in Mexico. Journal of International Relations, Strategy and Security [online], Date of consultation: February 20, 2017. Available: $<$ http://www.redalyc.org/articulo.oa?id=92731211003> ISSN 1909-3063.

[8] Popham, W. J. (1980): Problems and Techniques of Educational Evaluation. Ed. Anaya. Madrid Spain.

[9] García Ramos, J. M. (1989). Pedagogical bases of evaluation. Ed. Synthesis. Madrid. Spain.

[10] Mejía Pérez, Omar (2012). From traditional assessment to a new competency-based assessment. Autonomous University of Fresnillo, Educare Electronic Magazine Vol. 16, No. 1. Cuernavaca, Morelos, Mexico.

[11] Chomsky, Noam. (1969). The object of education. Ed. Ministry of Education. Spain.

[12] Gracia, Ma. Amalia, Horbath, Jorge E. (2014). The Educational Evaluation in Mexico. Journal of International Relations, Strategy and Security [online], Date of consultation: February 20, 2017. Available: $<$ http://www.redalyc.org/articulo.oa?id=92731211003> ISSN 1909-3063.

[13] Canadian Journal of Educational Administration and Policy, Issue \#67, January 14, 2007. (C) by CJEAP and the author(s).

[14] Catherine E. Casey_\& Ruth A. Childs. (January 14, 2007). Teacher Education Program Admission Criteria and What Beginning Teachers. Need to know to be Successful Teachers. Ontario Institute for Studies in Education of the University of Toronto. 